\title{
CHILDREN-FRIENDLY DESIGN OF URBAN PUBLIC SPACE based on the study of shanghai,china
}

\author{
Author SHUAI LI, Tongji University; China
}

\begin{abstract}
At present, more than 50\% of children live in big cities.But with the increasing number of motor vehicles and shrinking public spaces, children have less and less opportunities for outdoor activities, resulting in obesity and sub-health problems. Therefore, it is very important to build children-friendly public spaces in metropolis. This study takes the Shanghai,china as an example.Firstly, through questionnaires, it is found that ensuring the safe movement of children and inspiring their spontaneous activities are key points to build children-friendly public spaces.Meanwhile, The public spaces near the home are the most used environment by children. Therefore, open spaces in metropolis areas need to be planned carefully for children near their homes.Then it is way much better to make sure children's places of daily life, such as homes, schools, green spaces, sports venues and so on, can be connected in a safe path. Secondly, for building the safe path for children, the safety of each spot along the path is analyzed by SP method, which is a mathematical algorithm, in order to find the risk factors and to avoid them in the future. Then we establish the action plan of "line space + point space" to build the children-friendly urban public space system. Line space refers to meeting the basic safety space needs of children through the improvement of the routes to school, including reducing the impact of motor vehicles, safe road facilities, and enhancing road lighting system. "Point space" refers to the promotion of children's outdoor activities through the arrangement of multi-level outdoor children's playgrounds and green spaces, including safe green parks, security platforms and so on. Finally, it is hoped that the "Safety Line Space + Interesting Point Space" plan will establish a safe and inspiring path for children to travel,linking home, school, green space and sports venues, which they use mostly in their daily life. Then we can ensure the safe movement of children and inspire children's spontaneous games in big cities for a children-friendly goal.
\end{abstract}

\section{Keywords}

Child-friendly design, Children's independent mobility(CIM), Safe path space,Stated preference(SP) method

\section{Theoretical research}

\subsection{Child-friendly city}

The concept of Child Friendly City ( CFC) was put forward at the Second UN Conference on Human Settlement Environment in 1996. The meaning of CFC is: a city governance system that can hear the voice of children and realize their needs, priorities and rights (Shen , 2015). The goal is to reach the four basic rights of children : the right to subsistence, the right to development, the right to protection and the right to participation. In the same year, in order to 
make the world aware of the importance of big cities for children's growth and the urgency of response measures, UNESCO launched the "Growing up in the City" (GUIC) plan, and proposed that children can walk safely on the streets alone, meet and play with other children, live in an environment free of pollution and green space, and upgrade the original neighbourhood.

Thus, the Netherlands, Austria and other places carry out a large number of systematic practices, and become a global model. The research on the relationship between children and urban space in China starts around 1990. Some scholars use Beijing, Shanghai and other big cities as objects to find that the playspace in business complex gradually become an important space for city children (Li,1999), or set up safety facilities in high-rise residential areas and point out specific guidance (Shen,2015). Until recent years, Changsha, Shenzhen and other cities have put forward the slogan of creating child-friendly cities.

\subsection{Spatial influence factor of children's independent mobility(CIM)}

"Children can walk safely on the street alone" is the four construction principles of building a child-friendly city in GUIC plan.Over the past decades, the degree of freedom of children under 18 years of age to engage in public space activities without adult companionship has declined dramatically (Hillman et al., 1990; Kingham \& Usher, 2007). It causes that increased use of cars to pick up children; increased obesity among children; reduced use of public spaces such as parks and streets; and increased fear of strangers among children (Malone, 2007). At the same time, Kingston (2007) pointed out that if five-year-olds could not play independently, they would not be able to actively interact with their peers and would be more dependent on their mothers, which to some extent led to the aggravation of obesity, autism, violence and anti-social problems of urban children. Therefore, many scholars are focusing on the influence factor, especially on building environment of public space .

Table 1 Spatial influence factor of CIM according to references

\begin{tabular}{|c|c|c|c|}
\hline auther & country & sample & Spatial Influencing Factors \\
\hline $\begin{array}{l}\text { Leobach and } \\
\text { Gi11iland (2014) }\end{array}$ & Canada & 143, girls $=94$, boys $=49$ & $\begin{array}{l}\text { Residential location type, distance from } \\
\text { home to school, people density, land use } \\
\text { mix, proportion of people, commercial land } \\
\text { use, intersection density, road density }\end{array}$ \\
\hline Villanueva (2012) & Australia & $\begin{array}{l}1132, \text { girls=499, } \\
\text { boys }=478\end{array}$ & Distance from home to school \\
\hline kytta $(2004)$ & Finland & $\begin{array}{l}223, \text { girls }=80, \\
\text { boys }=147\end{array}$ & Recreational facilities \\
\hline Islam (2014) & Bangladesh & 109, girls $=42$, boys $=67$ & $\begin{array}{l}\text { Proportion of residential, commercial land } \\
\text { use, intersection density, dead end } \\
\text { street, vehicular street width }\end{array}$ \\
\hline $\begin{array}{l}\text { Broberg and } \\
\text { Sarjala }(2015)\end{array}$ & Finland & $\begin{array}{l}202, \operatorname{gir} 1 \mathrm{~s}=108, \\
\text { boys }=94\end{array}$ & $\begin{array}{l}\text { Distance from home to school, people } \\
\text { density, recreation density, road } \\
\text { density, proportion of main roads }\end{array}$ \\
\hline Carver (2014) & UK & $\begin{array}{l}\text { 977, girls }=499 \\
\text { boys }=478\end{array}$ & $\begin{array}{l}\text { Land use mix, road density, proportion of } \\
\text { main roads }\end{array}$ \\
\hline
\end{tabular}




\begin{tabular}{|c|c|c|c|}
\hline Broberg (2013) & Finland & 901 & $\begin{array}{l}\text { Distance from home to school, residential } \\
\text { density }\end{array}$ \\
\hline $\begin{array}{l}\text { Fyhri and } \\
\text { Hjorthol (2009) }\end{array}$ & Norway & $\begin{array}{l}1282, \text { girls }=705 \\
\text { boys }=577\end{array}$ & Distance from home to school \\
\hline Christian(2015) & Austrilia & $\begin{array}{l}\text { 181, girls=100, } \\
\text { boys=181 }\end{array}$ & $\begin{array}{l}\text { Distance from home to school, recreational } \\
\text { facilities }\end{array}$ \\
\hline lin chang (2009) & Taipei & 168 & $\begin{array}{l}\text { Distance from home to school, intersection } \\
\text { density, vehicular street width, residential } \\
\text { location type }\end{array}$ \\
\hline Monsur (2011) & Bangladesh & 60, girls $=16$, boys $=44$ & $\begin{array}{l}\text { Distance from home to school, recreational } \\
\text { facilities, dead-end street, vehicular } \\
\text { street width }\end{array}$ \\
\hline
\end{tabular}

We can see that distance from home to school ( 8 times in the table), density of recreational facilities (5), density of intersections (4), density of people flow (4), land use (2), width of traffic roads (2), proportion of commercial land (2), proportion of main roads (2), population composition (1), proportion of commercial land (1) all affect children's independence. Significant indicators of travel are established.

\subsection{Stated Preference Method}

Stated Preference Method is a spatial research method based on user preference, that is, "people's subjective preference for multiple alternatives under hypothetical conditions" (Fang, 2015). The SP method obtains people's spatial environment preferences in complex situations through scenario preference questionnaire, and can anticipate factors that do not exist, so it can be easily transplanted to the planning and design of spatial environment. It is widely used in traffic analysis and environmental assessment abroad (Louviere, 2000). However, domestic research is relatively late. Fang (2015) uses SP method to study the recreational preferences of Shanghai residents'country parks, and puts forward specific research paths of SP method. Zhu(2016) is conducive to SP method to study the evaluation and optimization of urban road bicycle travel environment in Shanghai. The research path of SP method is as follows: firstly, through pre-investigation, obtain spatial elements and levels; through orthogonal design, extract preference options, form questionnaires; data collection, establish discrete selection model and other major steps.

STRP1: Pre-survey: Determining Elements and Levels STEP2: Orthogonal Design to Extract Selection

STEP3: Data Collection and Establishment of Discrete Selection Model

STEP4: Analytical Model, Practical Application

Figure 14 steps of SP method

\section{Research Design}

\subsection{Subject: City children (Grade 4-6)}

The object of this study is children in urban environment. According to the research of children's developmental psychology, children aged 6-12 use outdoor space most actively. Children aged 10-12 have mature acceptance of concepts and self-reaction ability. The research on children's independent and safe walking path space is mainly aimed at children 
aged 10-12.According to the situation of China.,the age corresponds to children are grades 4 to 6 in primary school. Therefore, two primary school students of 4-6 th grade are selected as the main research objects (Fig. 2). The surrounding built environment is rich, close to the city's commercial center, with typical urban road organization, high traffic density, many shops and other city conditions.

\subsection{Pre-survey design}

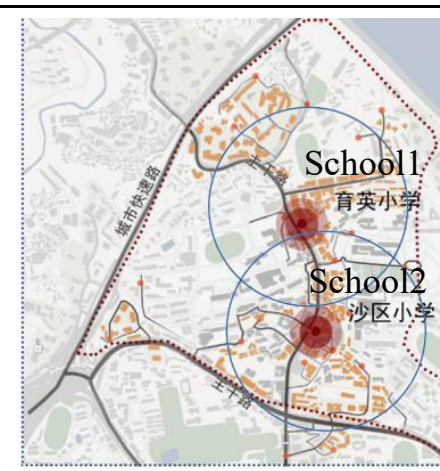

Figure 2 Research area

As for the pre-survey, the questionnaire needs to determine and evaluate the relevant elements and levels of children's safe path space to school. Firstly, the parents and students in the survey area were pre-surveyed by combining 10 significant indicators affecting children's safely individual movement with 15 indicators collected from existing studies. Each respondent selected the most influential factors to them. Finally, 10 factors related to the creating of safe path are identified, and the uncontrollable elements of children's psychological planning are eliminated. Each factor contains 2-4 levels. The definition and level of these elements are shown in Table 2. Level 1 is the most safe category for parents and students, while the effect of other levels decreases at one time. These elements are divided into three categories: path space elements, path traffic elements and path social elements. Spatial factors include distance from home to school, recreation place, danger place, proportion of commercial land use; path traffic factors include vehicle flow, number of crossing the street, cross street help ; path social factors include density of people,people composition, density of Help-seeking facilities.

Table2 Influence factors and levels by pre-survey

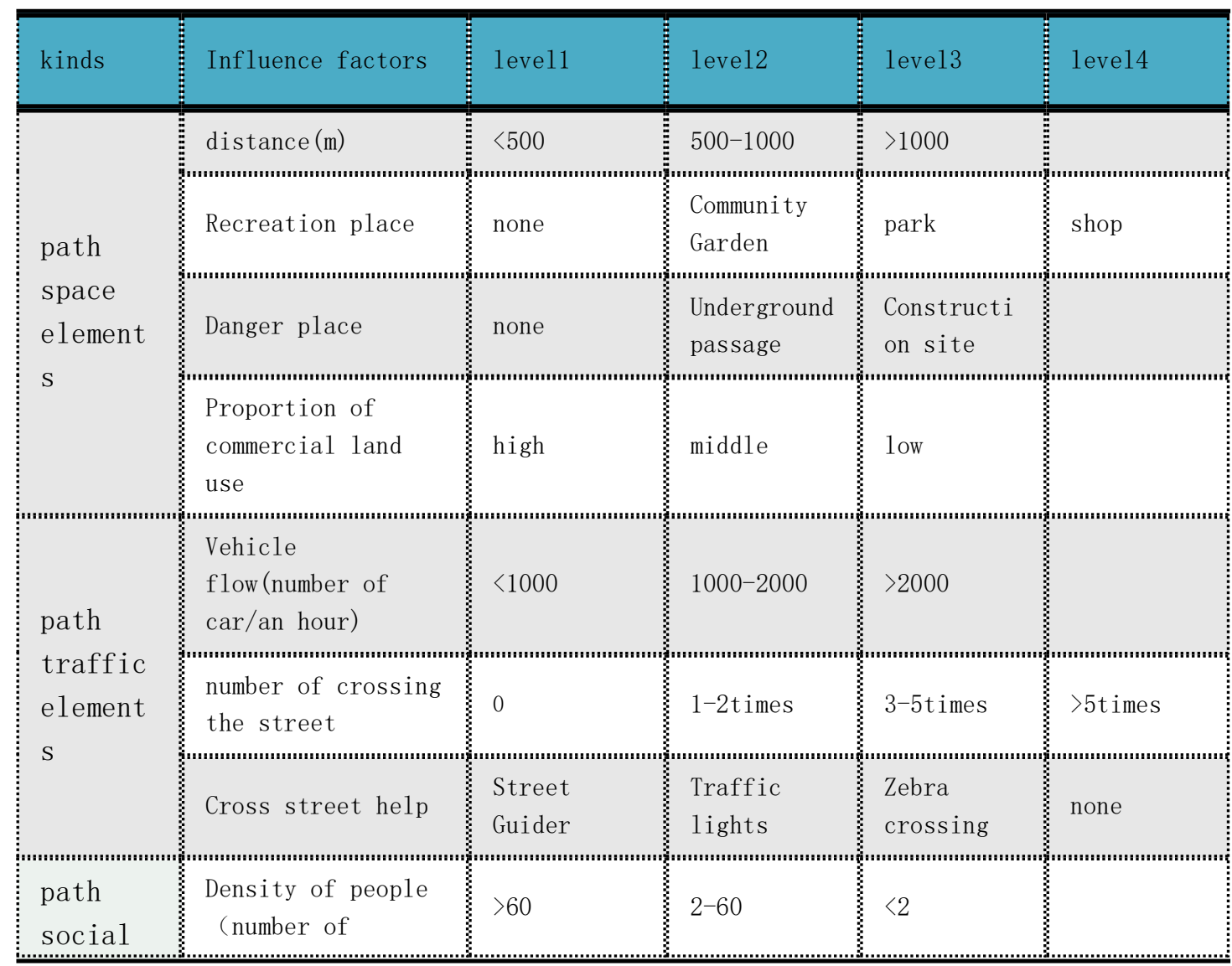




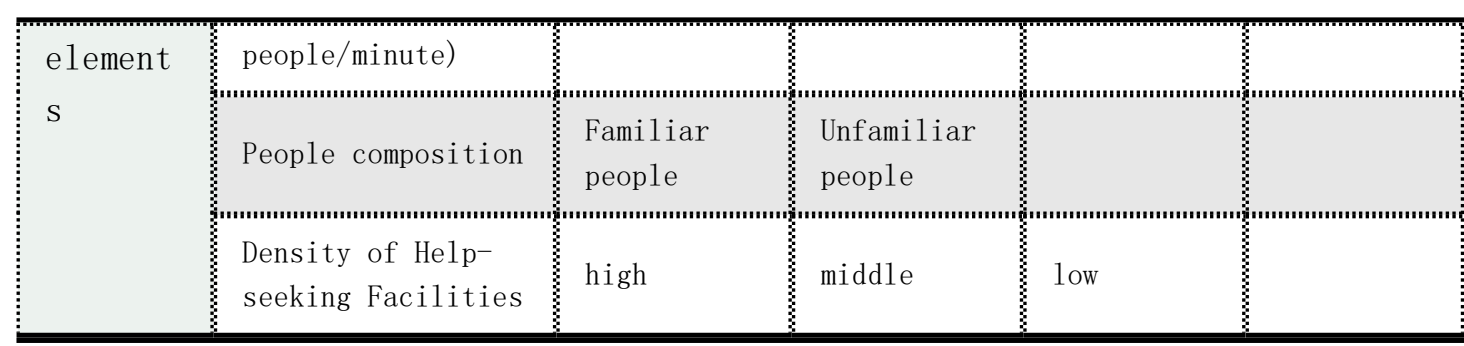

\subsection{Data collection}

Based on SP method, the questionnaires let the children and their parents choose the best one among the two virtual children's paths, and use SPSS to orthogonalize them, resulting in 128 paths with representative, homogeneous and independent elements, 64 selection scenarios, which were randomly distributed to the subjects in five sets of questionnaires. The axonometric mapping of children's school path elements is placed on both sides of the text description comparison table, and the related influencing factors on the path are visually represented by the graphic (Figure 4), so that the respondents can make quick choices without looking at the table. The online questionnaire is combined with the field survey. 158 valid questionnaires for parents were collected.

\begin{tabular}{|l|l|l|}
\hline \multicolumn{2}{|l|}{ Choise 10. Which path do you think is more safer? } \\
\hline Path 1 & Influence factors & Path 2 \\
\hline $500-1000$ & distance (m) & $500-1000$ \\
\hline none & Recreation place & shop \\
\hline \hline Underground passage & Danger place & Construction site \\
\hline$<1000$ & Proportion of commercial land use & $>2000$ \\
\hline $1-2$ times & Vehicle flow (number of car/an hour) & 0 \\
\hline Traffic lights & number of crossing the street & Traffic lights \\
\hline Street Guider & Cross street help & none \\
\hline $2-60$ & Density of people (number of people/minute) & $>60$ \\
\hline Familiar people & People composition & Familiar people \\
\hline high & Density of Help-seeking Facilities & high \\
\hline
\end{tabular}
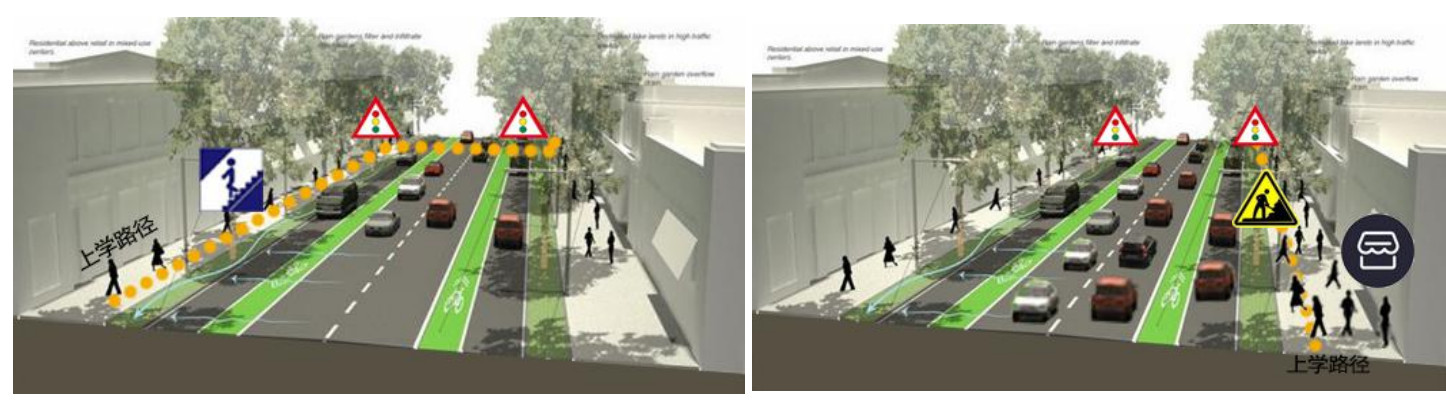

Figure 3 question example in the questionnaire 


\section{Spatial Preference Model of Children's Safety Routes}

\subsection{Model Construction}

The SP method obtains the relative importance of each factor through parents and children 'view on children's safe path selection, which is in line with the theoretical basis of discrete choice model - stochastic utility theory. According to this theory, the effect of safe environment on parents is the judgment basis when individuals make choices, that is, when respondents answer questionnaires, they will choose the most effective safe environment for them to go to and from school. The expression of the discrete selection model used in this paper is as follows:

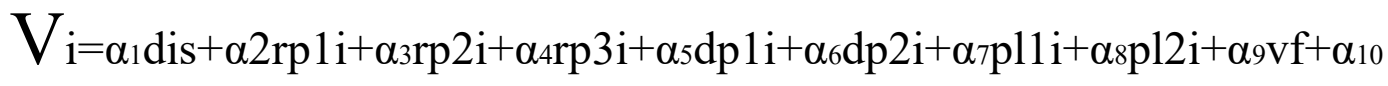

$$
\begin{aligned}
& \text { nc } 1 \mathrm{i}+\alpha_{11} \text { nc } 2 \mathrm{i}+\alpha_{12} \text { nc } 3 \mathrm{i}+\alpha_{13} \operatorname{cs} 1 \mathrm{i}+\alpha_{14} \operatorname{cs} 2 \mathrm{i}+\alpha_{15} \mathrm{cs} 3 \mathrm{i}+\alpha_{16} \mathrm{dop}+\alpha_{17} \mathrm{pc} 1 \mathrm{i}+\alpha_{18} \mathrm{do} \\
& \text { hcfli }+\alpha_{19} \text { dohcf } 2 \mathrm{i}
\end{aligned}
$$

In the formula, I is the choice of the path, I is the plan of choosing different children's paths to and from school. Vi is the visible utility of choosing a certain path. $\alpha 1-19$ is the element to be fitted by the model. The other variables are the important impact indicators listed in Table 2.

\subsection{Model Results}

Using Nlogit5 software to fit the model, the results are as follows: Table 3, which shows the mean value of variable parameters, and also the parameters used in subsequent evaluation applications. The overall goodness of fit of the model is Rho Square $=0.3598$, which is a good result in similar studies. Except for the medium density of help-seeking facilities (significance 0.84) and the construction site (significance 0.798) in the hidden danger space elements, the parameters of all variables have reached a high statistical significance, and accord with the common sense. According to this analysis, most of the construction sites in the city have obvious protection and isolation measures, and urban children have a strong sense of prevention, so the effectiveness of this experiment is not significant. At the same time, parents think that medium-density rescue facilities such as alarm booths and patrol posts are not enough for children's safety. They should increase the layout density, so the indicators are not significant.

Table3 Model results from Nlogit5

\begin{tabular}{l|l|l|l|l}
\hline \multirow{2}{*}{ factors } & level & $\begin{array}{l}\text { Level in } \\
\text { model }\end{array}$ & $\begin{array}{l}\text { parameter } \\
\text { values }(a)\end{array}$ & $\begin{array}{l}\text { Significa } \\
\text { nce }\end{array}$ \\
\hline \hline distance (m) & continuous variable & dis & -0.0086 & $<0.0 .05$ \\
\hline \hline \multirow{3}{*}{ Recreation place } & none & - & 0 & - \\
\cline { 2 - 5 } & community Garden & rp1 & -2.23264 & $<0.001$ \\
\cline { 2 - 5 } & park & rp2 & -1.01894 & $<0.001$ \\
\cline { 2 - 6 } & shop & rp3 & -0.1661 & $<0.001$ \\
\hline \hline
\end{tabular}




\begin{tabular}{|c|c|c|c|c|}
\hline \multirow[t]{3}{*}{ Danger place } & none & - & 0 & - \\
\hline & underground passage & $\mathrm{dp} 1$ & -1.3651 & $<0.001$ \\
\hline & construction site & $\mathrm{dp} 2$ & -0.57926 & 0.7928 \\
\hline \multirow[t]{3}{*}{$\begin{array}{l}\text { Proportion of } \\
\text { commercial land } \\
\text { use }\end{array}$} & high & - & -2.48264 & $<0.001$ \\
\hline & middle & pl1 & -1.56894 & $<0.001$ \\
\hline & low & p12 & -0.5861 & $<0.001$ \\
\hline $\begin{array}{l}\text { Vehicle } \\
\text { flow (number of } \\
\text { car/an hour) }\end{array}$ & continuous variable & $\mathrm{vf}$ & -0.21278 & $<0.001$ \\
\hline \multirow{4}{*}{$\begin{array}{l}\text { number of crossing } \\
\text { the street }\end{array}$} & none & - & 0 & - \\
\hline & $1-2$ times & nc1 & -0.12355 & $<0.005$ \\
\hline & $3-5$ times & nc2 & -0.21278 & $<0.001$ \\
\hline & $>5$ times & nc3 & -0.35482 & $<0.005$ \\
\hline \multirow{4}{*}{ Cross street help } & street guider & - & 0 & - \\
\hline & traffic lights & $\operatorname{cs} 1$ & 0.06709 & $<0.001$ \\
\hline & zebra crossing & $\operatorname{cs} 2$ & -0.11536 & $<0.001$ \\
\hline & none & $\operatorname{cs} 3$ & -0.80477 & $<0.001$ \\
\hline $\begin{array}{l}\text { Density of people } \\
\text { (number of } \\
\text { people/minute) }\end{array}$ & continuous variable & dop & 0.284 & $<0.001$ \\
\hline \multirow{3}{*}{$\begin{array}{l}\text { Density of Help }{ }^{-} \\
\text {seeking Facilities }\end{array}$} & high & - & 0 & - \\
\hline & middle & dohcf1 & -0.50889 & $<0.001$ \\
\hline & low & dohcf2 & -0.07749 & $<0.84$ \\
\hline
\end{tabular}

Log-1ikehood $=-59.04922$

Rho Squar $=0.3598$

Note: Some variables have no specific measurement index, so they are in the form of virtual variables. In each variable, the lowest level of utility is set at 0 , compared with other levels. 
The model constructed in this paper is the utility model of children's safe routes to school. The idea is to find out some factors affecting children's safety and to avoid them. The optimal level of the elements is set to 0 , and the reference values are mostly negative, which shows that the selected elements have a negative impact on the safety of the path (Fig. 5).

From the results, we can see that among the three factors, the path space factor, the path traffic factor and the path social factor have a significant impact on children's school safety. Among them, the path space factor and the path traffic factor are the main factors affecting parents'judgment.

In terms of road space elements, recreation place in urban path elements become the most worrying factor for parents, especially the community garden and park. Through interviews and analysis, it is known that children in cities have less space for outdoor activities, and the special outdoor space for children is also scarce. While playing in general space, children are more likely to encounter collisions, falls, scratches and other injuries when playing. At the same time, Parents are more worried that the lower proportion of commercial space will be dangerous to children because of the vitality of streets and the reduction of crowds. Finally, we found that the farther away from school, the lower the utility, but the impact is not significant. Because in the current urban environment, high-quality teaching resources are not fully distributed equally, parents let students enter a far schoo for better educational resources, andparents do not think that distance factors will bring more harm.

In terms of road traffic elements, motor vehicle traffic is not as worrying to parents as it is in the traditional sense. Parents are worried about whether their children can get help in the process of crossing the road and the number of times they cross the road. Because in the urban environment, the impact of motor vehicles is inevitable, the number is not terrible..But the number of roads has a significant impact, and the more the number of times, the greater the degree of concern of parents. Meanwhile zebra crossing is not safe in the eyes of parents. Only street lights and street guide without assistant crossing can improve the safety of the path.

In terms of path social factors, the density of human flow has a positive impact on safety utility, and the greater the density of human flow, the higher the safety utility. However, the composition of the population has no significant impact on the utility. It may be that in the urban mobility environment, it is difficult for parents and children to find a large number of familiar people. Meanwhile, the medium and low density of help-seeking facilities have a negative impact on the safety utility. Parents believe that only high density security posts, patrol mobile platforms and so on can guarantee children's safety.

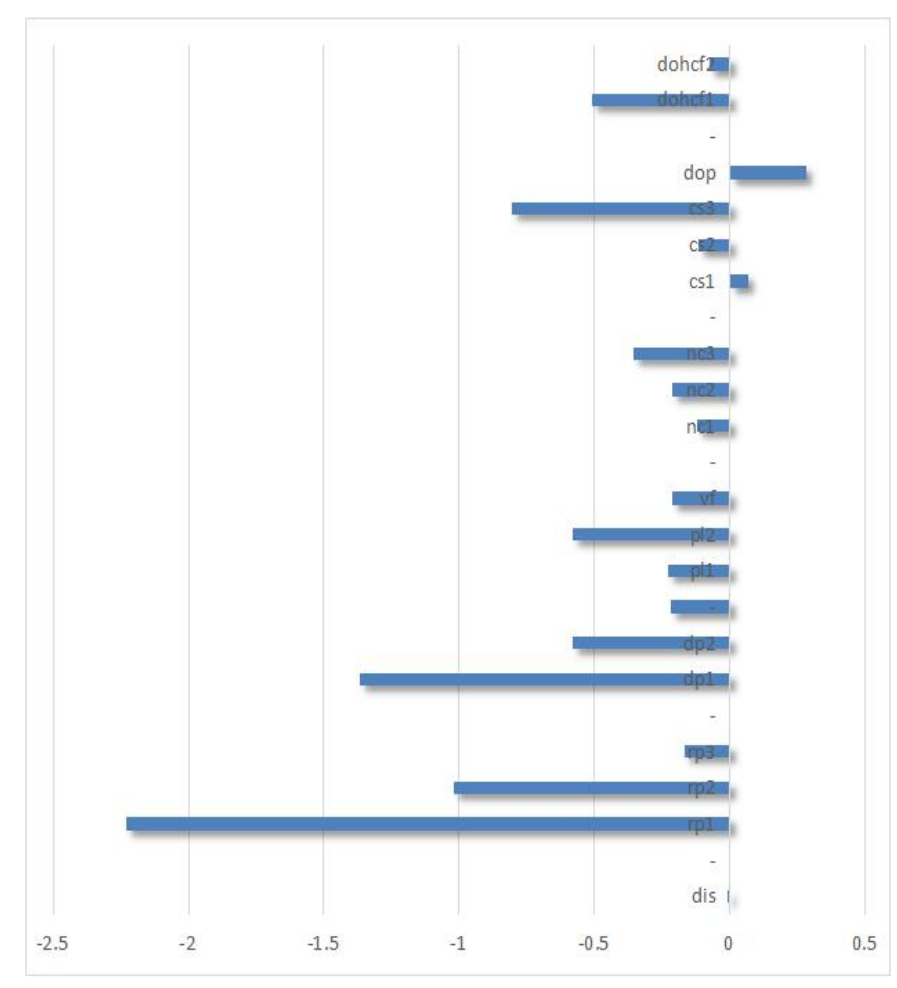

Figure 4 Model results 


\section{Conclusion}

Based on the above model, we can find the preference for the spatial factors of children's safe path of public space in high-density urban environment. It is found that the factors of path space, path traffic and path society have significant effects on children's safety. Among them, the path space factor and the path traffic factor are the most important factors.And recreation place 、 dangerous place 、 crossing the street without any help are the top 3 influential factors. Therefore, we can modify and adjust the most effective indicators one by one.

Firstly, for path space element.Recreation place on the way are the first objects to be adjusted, which have the greatest impact on children's safety, especially the open public space most commonly used by children such as community parks and street corner parks.. At the same time, Attention need to be paid on dangerous space such as underground passage. They also need to maintain a certain proportion of commercial space of children's way to and from school, so as to form vitality and gather people, so as to provide more weight for children. Social public protection.

Secondly, for path traffic element.We need to improve the traffic assistance for children when crossing the street. The high traffic volume in the city can not be changed. What parents really worry about is whether the children have assistant facilities such as street guide, traffic lights, zebra crossing and so on in the process of crossing the street. In the case of crossing the street, the safety effectiveness shows positive value. At the same time, the relevant signs such as student's path guide board can also play a positive role. Effect.

Thidly,for path social element. We can increase the density of students'help-seeking facilities and increase patrol posts and mobile security platforms during the period of students' going to and from school. At the same time, urban space should pay attention to the attraction of the density of human flow and create a good public space atmosphere, which will also bring positive effects on children's safety.

Finally we establish the action plan of "line space + point space" to build the children-friendly urban public space system. Line space refers to meeting the basic safety space needs of children through the improvement of the routes to school, including reducing the impact of motor vehicles, helping children to across the street, setting crossing points near schools during school hours,increasing the density of students'help-seeking facilities. "Point space"

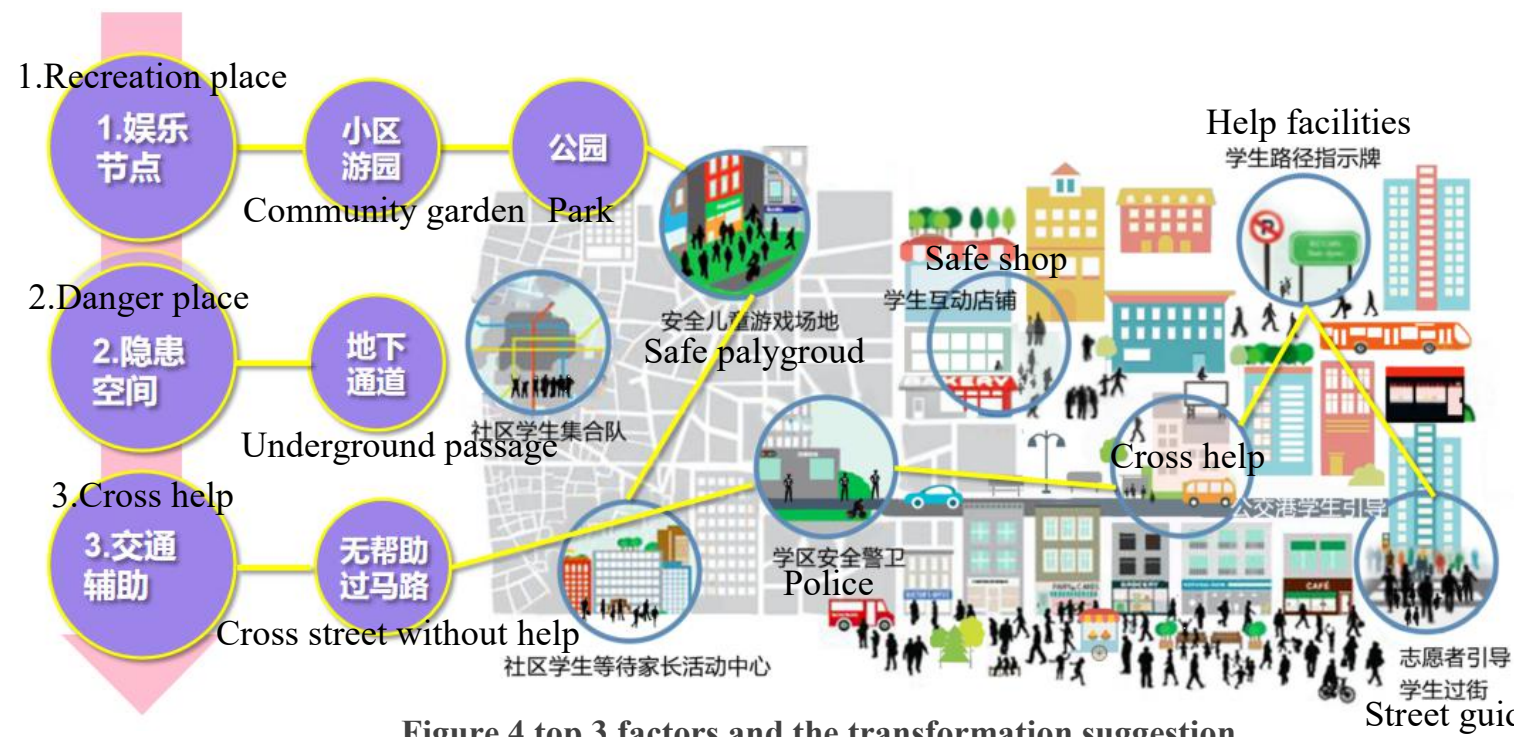

Figure 4 top 3 factors and the transformation suggestion 
refers to the promotion of children's outdoor activities through the arrangement of multi-level outdoor children's playgrounds and green spaces, including safe green parks, security platforms and so on. Hope this through this study, we can provide a reference evaluation index for children's safe travel space environment in high density urban environment, and also provide the steps and key points for regional transformation.

\section{References}

Shen Yao;Kinoshita Isami;He Lei(2015) "Study on the development characteristics and redeveloping direction of children's playing space in high-rise housing estate" Human Geography,Vol.30NO.3(June)

Li hongyu;Xu shaoming(1999) “ The play space of children in city " New architecture, Vol.25 NO.6(February)

Loebach, J.E.;Gi1li1and, J.A. ( 2014 ) “Free range kids? Using GPS-derived activity examine childrens neighborhood activity and mobility" . Environ. Vol.48 NO.3 421-453.

Villanueva. K, Gi1 es-Corti. B;Bnlsara. M;McCormack, G.R.;Timperio, A.;Middleton, N., Beesley, B;Trapp, G. ( 2012 ) “How far do children travel from their homes? ” Health Place. Vol. 18 No. 2 , 263-273.

Kytta, M ( 2004 ). “ The extent of children's independent mobility and the number of actualized affordances as criteria for child-friendly environments" Environ Psvchol. Vol. 24 No. $2,179-198$.

Islam ， M.Z.;Moore,R.;Cosco,N. （2014 ） “ Child-friendly,active,healthy neighborhoods:physical characteristics and childrens time outdoors " Environ.Behav.Vol. 48 No. 5 , 711-7.

Broberg, A;Satjala, S ( 2015 ) “School travel mode choice and the characteristics of the urban built environment: the case of Helsinki, Finland” . Transport Policy. Vol. 37 , $1-10$

Carver, A.; Panzer, J.R;Jones, A.P.; van Sluijs, E.M. (2014) “ Independent mobility on the journey to school: a joint cross-sectional and prospective exploration of social and physical environmental influences.” Journal of Transport\&Health. Vol. 1 No. 1,2532 .

Broberg, A.;Salminen, S.; Kytta,M ( 2013 ) “ Physical environmental characteristics promoting independent and active transport to children's meaningful places” . Appl Geogr. No.38,43-52.

Fyhri, A;Hjorthol. R ( 2009 ) “Children's independent mobility to school, friends and leisure activities” J. Transp. Geogr.Vol. 17No. 5,377-384.

Christian. H.E;Klinker, C.D;Villanueva. K;Knuiman. MW;Foster, S.A; Zubrick, S.R;Divitini. M;Wood. L;Giles-Corti.,B. ( 2015 ) “ The effect of the social and physical environment on children's independent mobility to neighborhood destinations" . I.Phys. Act. Health 12 (Supply 1), S84-S93. 
Lin ,J.J.;C:hang, H.T. ( 2009 ) “ Built environment effects on children's school travel in Taipai” : independence and travel mode. Urban Stud. Vol. 47 No. 4 , 867-889.

Monsur, M., Islam,Z. (2011) “Impact of street design on children's independent mobility in Dhaka city” . 82-88

Fang jia;Wang de;Zhu wei;Song shan ( 2015 ) “ Residents' recreation preference of the country park in Shanghai:a stated-preference analysis” .LA Planning and Design. No. 6(May)

Louviere J J, et al (2000) Stated Choice Methods: Analysis and Applications Kindle Editio Cambridge University Press.

Zhu wei;Zhai baoxin;Jian dan (2016) "Evaluation and optimization of urban bicycle travel environment based on a visualized SP method" Urban Planning. No. 3 (March) 